\title{
PENGARUH MOBILISASI PROGRESIF TERHADAP STATUS HEMODINAMIK PADA PASIEN KRITIS DI INTENSIVE CARE UNIT
}

\author{
Wahyu Rima Agustin ${ }^{1,}$, Gatot Suparmanto ${ }^{2}$, Wahyuningsih Safitri ${ }^{3}$ \\ ${ }^{1,2,3}$ Prodi Profesi Ners Universitas Kusuma Husada Surakarta \\ ${ }^{1}$ wra.wahyurimaagustin@gmail.com*
}

\begin{abstract}
Abstrak
Latar Belakang : Salah satu intervensi yang dilakukan oleh perawat di pelayanan intensif adalah pemberian mobilisasi progresif. Namun pentingnya pemantauan hemodinamika pada pasien kritis maka perlu diperhatikan dalam memberikan mobilisasi progresif.

Tujuan : Tujuan dari penelitian ini untuk mengetahui pengaruh mobilisasi progresif terhadap status hemodinamik pada pasien kritis di ICU RSUD Karanganyar.

Metode : Desain penelitian menggunakan metode quasi eksperimen dengan prepost without control design. Pengukuran dengan lembar observasi untuk menilai Heart Rate (HR), Respiratory Rate (RR), saturasi oksigen $\left(\mathrm{SaO}_{2}\right)$, Tekanan Darah dan Mean Arterial Pressure (MAP) sebelum dan sesudah diberikan mobilisasi progresif. Pengambilan sampel dengan cara purposive sampling, sejumlah 19 responden. Penelitian ini dilaksanakan selama 1 bulan pada bulan oktober 2018.

Hasil : Hasil analisis bivariat didapatkan ada perbedaan bermakna antara Heart Rate (HR), Respiratory Rate (RR), saturasi oksigen $\left(\mathrm{SaO}_{2}\right)$, Tekanan Darah (BP) dan Mean Arterial Pressure (MAP) sebelum dan sesudah mobilisasi progresif dengan dengan $p$ value 0,000 dan 0,037 ( $\mathrm{p}<0,05$ ). Hasil penelitian ini menyarankan mobilisasi progresif tetap diberikan pada pasien kritis untuk meningkatkan kualitas hidup pasien dengan memperhatikan status hemodinamika pasien. Terjadi peningkatan status hemodinamik setelah dilakukan mobilisasi progresif dalam batas normal.
\end{abstract}

Simpulan : Mobilisasi progresif berpengaruh meningkatkan status hemodinamik pada pasien kritis.

Kata kunci: Mobilisasi Progresif; Status Hemodinamika; Pasien Kritis

\section{THE EFFECT OF PROGRESSIVE MOBILIZATION OF STATUS HEMODYNAMICS IN CRITICAL PATIENTS IN INTENSIVE CARE UNIT}

\footnotetext{
Abstract

Background : One of the interventions conducted by nurses at intensive care is the administration of progressive mobilization to critical patients. When conducting the progressive mobilization, attention must be paid to hemodynamic monitoring.

The Purpose:The objective of this research is to investigate the effect of progressive mobilization to the hemodynamic status of critical patients at the Intensive Care Unit of Local General Hospital of Karanganyar.
} 
Method: This research used the quasi-experimental method with pre-post without control design. Its data were collected through observation sheets to assess heart rate $(H R)$, respiratory rate $(R R)$, oxygen saturation $\left(\mathrm{SaO}_{2}\right)$, blood pressure $(B P)$, and mean arterial pressure (MAP) prior to and following the administration of progressive mobilization. 19 respondents were determined as the samples by using the purposive sampling technique. This research was conducted for 1 month in October 2018.

Result :There was a significant difference among the $H R$, the $R R$, the $B P$, and the $M A P$ prior to and following the administration of progressive mobilization as shown by the result of the bivariate analysis where the p-values were 0.000 and $0.037(p<005)$ respectively. Thus, there was an increase in the hemodynamic status of the patients within normal limit following the progressive mobilization. It is recommended that the administration of progressive mobilization be continued to critical patients to improve their life quality by keeping in mind their hemodynamic status.

Conclusion : Progressive mobilization has the effect of increasing hemodynamic status in critically ill patients.

Keywords: Progressive mobilization, hemodynamic status, critical patients

\section{PENDAHULUAN}

Intensive Care Unit (ICU) merupakan ruang rawat rumah sakit dengan staf dan perlengkapan khusus ditujukan untuk mengelola pasien dengan penyakit, trauma atau komplikasi yang mengancam jiwa (Musliha, 2010). Pasien dengan fase kritis dengan satu atau lebih gangguan fungsi sistem organ vital manusia yang dapat mengancam kehidupan serta memiliki morbiditas dan mortalitas tinggi, sehingga membutuhkan suatu penanganan khusus dan pemantauan secara intensif (Kemenkes RI, 2011). Pasien kritis memiliki kerentanan yang berbeda. Kerentanan itu meliputi ketidakberdayaan, kelemahan dan ketergantungan terhadap alat pembantu (Sunatrio, 2010).

Hasil studi di Amerika melaporkan prevalensi pasien kritis selama 20042009 terdapat 3.235.741 pasien yang mendapat perawatan ICU dan 246.151 (7,6\%) merupakan pasien kritis kronis. Pasien kritis kronis dengan sepsis $(63,7 \%)$ dan yang lainnya seperti stroke, luka parah, cidera kepala dan tracheostomy (Kahn et al, 2015). Data yang diperoleh dari buku registrasi pasien ICU RSUP Prof. Dr. R. D. Kandou Manado mulai dari bulan Januari-Oktober 2013 total pasien yang dirawat di ICU adalah sebanyak 411 pasien dan yang mengalami kejadian gagal napas sebanyak 132 pasien $(32,1 \%)$. Rata-rata pasien yang dirawat di ICU adalah 41-42 pasien/bulan dan rata-rata yang mengalami kejadian gagal napas adalah 1314 pasien/bulan serta 10-11 pasien/bulan meninggal akibat gagal napas (Kitong, BI, dkk, 2014). Di RSUD dr. Soediran Mangun Sumarso Wonogiri selama bulan Oktober-Desember 2015, pasien yang mendapatkan perawatan ICU terdapat 105 pasien, diantaranya pasien stroke, penyakit jantung dan diabetes mellitus.

Perawat merupakan salah satu bagian dari team ICU, yang mempunyai ruang lingkup luas, karakteristik unik serta peran yang penting dalam pemberian asuhan keperawatan kritis di ICU (Munawaroh dkk, 2012). Salah satu intervensi 
yang diberikan berupa perubahan posisi pasien dilakukan tiap 2 jam. Pasien yang dirawat di ruang ICU dengan gangguan status mental misalnya oleh karena stroke, injuri kepala atau penurunan kesadaran tidak mampu untuk merasakan atau mengkomunikasikan nyeri yang dirasakan atau pasien merasakan adanya tekanan namun mereka tidak bisa mengatakan kepada orang lain untuk membantu mereka mengubah posisi. Bahkan ada yang tidak mampu merasakan adanya nyeri atau tekanan akibat menurunnya persepsi sensori (Batticaca, 2012).

Pemantauan hemodinamika perlu diperhatikan, pemantauan tersebut merupakan suatu teknik pengkajian pada pasien kritis, mengetahui kondisi perkembangan pasien, serta untuk antisipasi kondisi pasien yang memburuk (Burchell \& Powers, 2011). Dasar dari pemantauan hemodinamika adalah perfusi jaringan yang adekuat, seperti keseimbangan antara pasokan oksigen dengan yang dibutuhkan, mempertahankan nutrisi, suhu tubuh dan keseimbangan elektrokimiawi sehingga manifestasi klinis dari gangguan hemodinamika berupa gangguan fungsi organ tubuh yang bila tidak ditangani secara cepat dan tepat akan jatuh ke dalam gagal fungsi organ multipel. Perawat sebagai bagian dari tim kesehatan dalam merawat pasien-pasien kritis mempunyai tanggung jawab yang besar dalam memonitor keadaan hemodinamik. Monitoring hemodinamik merupakan suatu pengkajian fisiologis yang penting dalam perawatan pasienpasien kritis (Prayitno dkk, 2015). Berdasarkan studi pendahuluan yang dilakukan peneliti di ICU RSUD Karanganyar didapatkan data jumlah tempat tidur di ICU sebanyak 4 tempat tidur. Pada bulan Agustus - september 2018 jumlah pasien yang dirawat diruang ICU sebanyak 36 pasien. Hasil wawancara dengan beberapa perawat mengatakan pasien yang dirawat diruang ICU hanya diberikan perubahan posisi miring kanan dan miring kiri setiap 2 jam. Perawat tidak memperhatikan status hemodinamik pada pasien sebelum dan sesudah diberikan posisi miring kanan dan miring kiri.

Mengingat pentingnya pemantauan status hemodinamika pada pasien kritis. Hal inilah yang mendorong peneliti untuk melakukan penelitian dengan tujuan mengetahui pengaruh mobilisasi progresif terhadap status hemodinamik pada pasien kritis di ICU RSUD Karanganyar.

\section{METODE}

Jenis penelitian ini yaitu penelitian kuantitatif dengan desain quasi experiment, dimana penelitian ini melakukan uji coba coba suatu intervensi pada sekelompok subyek dengan atau tanpa kelompok pembanding namun tidak dilakukan randomisasi untuk memasukkan subyek ke dalam kelompok perlakuan atau kontrol (Dharma, 2011).

Rancangan penelitian yang digunakan adalah one-group pretest-posttest design. Didalam desain ini observasi dilakukan sebanyak 2 (dua) kali yaitu sebelum dan sesudah intervensi pada satu kelompok perlakuan. Hasil perlakuan dapat diketahui lebih akurat, karena dapat membandingkan dengan keadaan sebelum diberikan perlakuan (Sugiyono, 2011). Penelitian ini dilakukan di ICU RSUD Karanganyar dan dilaksanakan selama 1 bulan pada bulan oktober 2018. 
Populasi pada penelitian ini adalah semua pasien kritis di ruang ICU RSUD Karanganyar, Teknik pengumpulan sampel pada penelitian ini menggunakan purposive sampling sejumlah 19 responden dengan kriteria inklusi $\mathrm{PaO} 2$ : FiO2 $>$ 250, nilai PEEP $<10$, suhu $<38^{\circ} \mathrm{C}$. RR $<30 \mathrm{x} /$ menit, HR $>60<120 \mathrm{x} /$ menit. MAP $>55<140$, tekanan sistolik berkisar $>90<180 \mathrm{mmHg}$, saturasi oksigen $>90 \%$, tingkat kesadaran pasien dengan respon mata baik (RASS -5 sampai -3). Kriteria eksklusi pasien dengan peningkatan tekanan intrakranial dan status hemodinamik tidak stabil.

Proses analisa data menggunakan one-group pretest-posttest design dengan menggunakan uji Paired sample t-test karena data terdistribusi normal untuk mengukur sebelum dan sesudah dilakukan mobilisasi progresif.

HASIL DAN PEMBAHASAN

Tabel 1.Karakteristik Responden $(\mathrm{n}=19)$

\begin{tabular}{|c|c|c|}
\hline Karakteristik & Frekuensi $(n=19)$ & Persentase \\
\hline \multicolumn{3}{|l|}{ 1. Umur } \\
\hline $40-59$ & 10 & 52,6 \\
\hline $60-79$ & 9 & 47,4 \\
\hline \multicolumn{3}{|l|}{ 2. Jenis kelamin } \\
\hline Perempuan & 12 & 63,2 \\
\hline Laki-laki & 7 & 36,8 \\
\hline
\end{tabular}

Tabel 1 Menunjukan karakteristik umur responden sebagian besar 40-59 tahun sebanyak 10 responden $(52,6 \%)$. Jenis kelamin responden pada penelitian ini sebagian besar berjenis kelamin perempuan sebanyak 12 responden $(63,2 \%)$.

Tabel 2.Analisis Rerata Heart Rate (HR), Respiratory Rate (RR), Saturasi Oksigen $\left(\mathrm{SaO}_{2}\right)$, Tekanan Darah dan Mean Arterial Pressure (MAP) Sebelum dan Sesudah Mobilisasi Progresif di RSUD Karanganyar(n=19)

\begin{tabular}{cccccccccccc}
\hline & \multicolumn{3}{c}{ Rerata Sebelum Mobilisasi Progresif } & \multicolumn{3}{c}{ Rerata Sesudah Mobilisasi Progresif } \\
\cline { 2 - 10 } Variabel & Mean & Median & SD & Min & Max & Mean & Median & SD & Min & Max \\
\hline Heart Rate $(\mathrm{HR})$ & 86,3 & 87,3 & 4,3 & 79 & 95,3 & 87,8 & 88,3 & 4,3 & 79,7 & 96,7 \\
$\begin{array}{c}\text { Respiratory Rate } \\
(\mathrm{RR})\end{array}$ & 18,6 & 18,3 & 3,4 & 14 & 25,3 & 19,9 & 19,7 & 3,1 & 15,3 & 26,3 \\
$\begin{array}{c}\text { Saturasi Oksigen } \\
\quad\left(\text { SaO }_{2}\right)\end{array}$ & 97,6 & 97,7 & 0,8 & 96 & 99 & 98,5 & 98,7 & 0,9 & 96,7 & 100 \\
$\begin{array}{c}\text { Tekanan darah } \\
\text { Sistolik }\end{array}$ & 127 & 126,7 & 12, & 98,7 & 146,7 & 128,7 & 127,3 & 10,9 & 107,7 & 149 \\
$\begin{array}{c}\text { Tekanan darah } \\
\text { Diastolik }\end{array}$ & 82,3 & 82,3 & 7,1 & 69 & 97 & 83,2 & 83 & 7 & 70,3 & 97,7 \\
$\begin{array}{c}\text { Mean Arterial } \\
\text { Pressure (MAP) }\end{array}$ & 98,3 & 99,7 & 3,8 & 90 & 103 & 99,1 & 105 & 4,2 & 91,3 & 105 \\
\hline
\end{tabular}

Tabel 2 menunjukkan rerata Heart Rate (HR) sebelum mobilisasi progresifadalah mean=86,3 dengan median=87,3 $\mathrm{SD}=4,3, \mathrm{~min}=79$ serta max=95,3. Rerata Respiratory Rate (RR) sebelum mobilisasi progresiadalah mean=18,6 dengan median=18,3, $\mathrm{SD}=3,4, \min =14$ serta $\max =25,3$. Rerata saturasi oksigen $\left(\mathrm{SaO}_{2}\right)$ sebelum mobilisasi progresifadalah mean=97,6 dengan median $=97,7, \mathrm{SD}=0,8, \min =96$ serta $\max =99$. Rerata tekanan darah sistolik 
sebelum mobilisasi progresif adalah mean=127 dengan median=126,7 $\mathrm{SD}=7,1$, $\min =7,1$ serta $\max =146,7$. Rerata tekanan darah diatolik sebelum mobilisasi progresif adalah mean $=82,3$ dengan median $=82,3, \mathrm{SD}=0,87, \mathrm{~min}=96$ serta max=99. Rerata Mean Arterial Pressure (MAP) sebelum mobilisasi progresifadalah mean $=98,3$ dengan median $=99,7, \quad \mathrm{SD}=3,8, \quad \min =90$ serta $\max =103$

Rerata Heart Rate (HR) sesudah mobilisasi progresif adalah mean $=87,8$ dengan median $=88,3, \mathrm{SD}=4,3, \min =79,7$ serta $\max =96,7$. Rerata Respiratory Rate (RR) sesudah mobilisasi progresif adalah mean $=19,9$ dengan median $=19,7$, $\mathrm{SD}=3,1, \min =15,3$ serta $\max =26,3$. Rerata saturasi oksigen $\left(\mathrm{SaO}_{2}\right)$ sesudah mobilisasi progresif adalah mean=98,5 dengan median=98,7 $\mathrm{SD}=0,9, \mathrm{~min}=96,7$ serta $\max =100$. Rerata tekanan darah sistolik sesudah mobilisasi progresif adalah mean $=128,7$ dengan median $=127,3, \mathrm{SD}=10,9, \min =107,7$ serta $\max =149$. Rerata tekanan darah diastolik sesudah mobilisasi progresif adalah mean=83,2 dengan median $=83, \mathrm{SD}=7, \min =70,3$ serta $\max =97,7$. Rerata Mean Arterial Pressure (MAP) sesudah mobilisasi progresif adalah mean $=99,1$ dengan median $=100,5$, $\mathrm{SD}=4,2, \min =91,3$ serta $\max =105$.

Sebelum dilakukan analisis bivariat dilakukan uji normalitas yang merupakan syarat utama melakukan uji parametik. Peneliti menggunakan uji normalitas dengan metode analisis parameter Shapiro-Wilk dengan kemaknaan (p) $>0,05$ (Dharma, 2011).

Tabel 3.Uji Normalitas Data Variabel Heart Rate (HR), Respiratory Rate (RR), Saturasi Oksigen $\left(\mathrm{SaO}_{2}\right)$, Tekanan Darah dan Mean Arterial Pressure (MAP)

Sebelum dan Sesudah Mobilisasi Progresif di RSUD Karanganyar (N=19)

\begin{tabular}{cllc}
\hline No & \multicolumn{1}{c}{ Variabel } & \multicolumn{1}{c}{ Pengukuran } & Shapiro-Wilk \\
\hline 1 & Heart Rate (HR) & Sebelum Mobilisasi Progresif & 0,584 \\
& & Sesudah Mobilisasi Progresif & 0,903 \\
2 & Respiratory Rate $(\mathrm{RR})$ & Sebelum Mobilisasi Progresif & 0,431 \\
\multirow{2}{*}{3} & \multirow{2}{*}{ Saturasi Oksigen $\left(\mathrm{SaO}_{2}\right)$} & Sesudah Mobilisasi Progresif & 0,799 \\
\multirow{2}{*}{4} & \multirow{2}{*}{ Tekanan Darah Sistolik } & Sebelum Mobilisasi Progresif & 0,800 \\
& & Sesudah Mobilisasi Progresif & 0,510 \\
\multirow{2}{*}{5} & Tekanan Darah Diastolik & Sebelum Mobilisasi Progresif & 1,000 \\
& & Sesudah Mobilisasi Progresif & 0,984 \\
\multirow{2}{*}{6} & \multirow{2}{*}{ Mean Arterial Pressure (MAP) } & Sebelum Mobilisasi Progresif & 0,615 \\
& & Sesudah Mobilisasi Progresif & 0,867 \\
& & Sebelum Mobilisasi Progresif & 0,590 \\
\hline
\end{tabular}

Hasil uji normalitas pada tabel 3. menunjukkan bahwa variabel Heart Rate (HR), Respiratory Rate (RR), Saturasi oksigen $\left(\mathrm{SaO}_{2}\right)$, Tekanan darah dan Mean Arterial Pressure (MAP) sebelum dan sesudah mobilisasi progresif $\mathrm{p}>0,05$ maka data terdistribusi secara normal sehingga menggunakan uji paired t test 
Tabel 4. Analisis Perbandingan Rerata Heart Rate (HR), Respiratory Rate (RR), Saturasi Oksigen $\left(\mathrm{SaO}_{2}\right)$, Tekanan Darah dan Mean Arterial Pressure (MAP)

Sebelum dan Sesudah Mobilisasi Progresif di RSUD Karanganyar $(\mathrm{n}=19)$

\begin{tabular}{|c|c|c|}
\hline Variabel & $\mathbf{t}$ & P value \\
\hline $\begin{array}{ll}\text { Heart Rate }(\mathrm{HR}) \\
-\quad \text { Sebelum } \\
-\quad \text { Sesudah } \\
\end{array}$ & $-5,686$ & 0,000 \\
\hline $\begin{array}{l}\text { Respiratory Rate (RR) } \\
-\quad \text { Sebelum } \\
-\quad \text { Sesudah }\end{array}$ & $-6,063$ & 0,000 \\
\hline $\begin{array}{l}\text { Saturasi Oksigen }\left(\mathrm{SaO}_{2}\right) \\
-\quad \text { Sebelum } \\
-\quad \text { Sesudah }\end{array}$ & $-7,852$ & $0,000^{8}$ \\
\hline $\begin{array}{l}\text { Tekanan Darah Sistolik } \\
-\quad \text { Sebelum } \\
-\quad \text { Sesudah } \\
\end{array}$ & $-3,445$ & $0,003^{*}$ \\
\hline $\begin{array}{l}\text { Tekanan Darah Diastolik } \\
-\quad \text { Sebelum } \\
-\quad \text { Sesudah }\end{array}$ & $-7,650$ & $0,000^{*}$ \\
\hline $\begin{array}{l}\text { Mean Arterial Pressure (MAP) } \\
-\quad \text { Sebelum } \\
-\quad \text { Sesudah }\end{array}$ & $-2,368$ & $0,037^{*}$ \\
\hline
\end{tabular}

Berdasarkan hasil statistik pada tabel 4. menunjukkan bahwa ada perbedaan yang bermakna antara Heart Rate (HR), Respiratory Rate (RR), saturasi oksigen $\left(\mathrm{SaO}_{2}\right)$ tekanan darah dan Mean Arterial Pressure (MAP) sebelum dan sesudah pemberian mobilisasi progresif ( $\mathrm{p}$ value $0,000 \leq 0,05$ ) berarti mobilisasi progresif mempengaruhi status hemodinamik pada pasien kritis di RSUD Karanganyar. Nilai t negatif menunjukkan bahwa Heart Rate (HR), Respiratory Rate (RR), saturasi oksigen $\left(\mathrm{SaO}_{2}\right)$, tekanan darah dan Mean Arterial Pressure (MAP) sebelum mobilisasi progresif lebih rendah dibandingkan setelah mobilisasi progresif

Heart Rate (HR) dengan nilai $p$ value 0,000 ( $\mathrm{p}<0,05)$. Heart Rate atau denyut nadi merupakan Denyut nadi (pulse rate) adalah gelombang yang disalurkan melalui arteri sebagai respons terhadap ejeksi darah dari jantung ke dalam aorta.10 Denyut nadi terbentuk seiring dengan didorongnya darah melalui arteri. Untuk membantu sirkulasi, arteri berkontraksi dan berelaksasi secara periodik, kontraksi dan relaksasi jantung seiring dengan dipompanya darah menuju arteri dan vena. Dengan demikian, denyut nadi (pulse rate) juga dapat mewakili detak jantung permenit atau yang dikenal dengan denyut jantung (heart rate). Denyut nadi dihitung tiap menitnya dengan hitungan repitisi (kali/menit) (Mustika, 2011).

Respiratory Rate $(\mathrm{RR})$ dengan nilai $p$ value $=0,000(\mathrm{p}<0,05)$. Respiratory Rate (RR) adalah jumlah napas yang dilakukan per menit. Dalam keadaan istirahat, kecepatan pernapasan sekitar 15 kali per menit (Pearce, EC, 2013). Pernapasan paru merupakan pertukaran oksigen dan karbondioksida yang terjadi pada paru. Fungsi paru adalah tempat pertukaran gas oksigen dan karbondioksida pada pernapasan melalui paru/pernapasan eksternal. Oksigen dipungut melalui 
hidung dan mulut. Saat bernapas, oksigen masuk melalui trakea dan pipa bronchial ke alveoli, dan dapat erat berhubungan dengan darah di dalam kapiler pulmonalis (Pearce, EC, 2013).

Saturasi oksigen $\left(\mathrm{SaO}_{2}\right)$ dengan nilai $p$ value $=0,000(\mathrm{p}<0,05)$. Saturasi oksigen adalah presentasi hemoglobin yang berikatan dengan oksigen dalam arteri, saturasi oksigen normal adalah antara 95 - $100 \%$. Dalam kedokteran, oksigen saturasi $\left(\mathrm{SaO}_{2}\right)$, sering disebut sebagai "SATS", untuk mengukur persentase oksigen yang diikat oleh hemoglobin di dalam aliran darah. Pada tekanan parsial oksigen yang rendah, sebagian besar hemoglobin terdeoksigenasi, maksudnya adalah proses pendistribusian darah beroksigen dari arteri ke jaringan tubuh. Pengukuran saturasi oksigen dapat dilakukan dengan beberapa teknik. Penggunaan oksimetri nadi merupakan tehnik yang efektif untuk memantau pasien terhadap perubahan saturasi oksigen yang kecil atau mendadak (Pinsky, M.R, 2019)

Tekanan darah dengan nilai $p$ value $=0,000(\mathrm{p}<0,05)$. Tekanan darah adalah gaya atau dorongan darah ke dinding arteri saat darah dipompa keluar dari jantung keseluruh tubuh, sedangkan tekanan darah adalah tenaga yang terdapat pada dinding arteri saat darah dialirkan. Tenaga ini mempertahankan aliran darah dalam arteri agar tetap lancar. Rata-rata tekanan darah normal biasanya 120/80 dan diukur dalam satuan milimeter air raksa $(\mathrm{mmHg})$ tekanan darah biasanya diukur secara tidak langsung dengan sphygmomanometer air raksa pada posisi duduk atau terlentang. (Burchell, et al, 2011)

Mean Arterial Pressure (MAP) dengan nilai $p$ value $=0,037(\mathrm{p}<0,05)$. Tekanan arteri rerata adalah gaya pendorong utama yang mengalirkan darah ke jaringan. Tekanan ini dipantau dan diatur di tubuh, bukan tekanan sistolik atau diastolik arteri atau tekanan nadi dan juga bukan tekanan di bagian lain pohon vaskular. Tekanan arteri rerata sedikit kurang daripada nilai-nilai tengah antara tekanan sistole dan diastole. Besar nilai pada orang dewasa sekitar $90 \mathrm{mmHg}$ yang sedikit lebih kecil dari rata-rata tekanan siastole dan diastole (Burchell, et al, 2011)

\section{SIMPULAN}

Berdasarkan hasil penelitian dan pembahasan bahwa mobilisasi progresif berpengaruh terhadap meningkatnya status hemodinamik, yang ditandai dengan meningkatnya Heart Rate (HR), Respiratory Rate (RR), saturasi oksigen $\left(\mathrm{SaO}_{2}\right)$, tekanan siastole dan diastole, dan Mean Arterial Pressure (MAP)pada pasien kritis di ICU RSUD Karanganyar.

\section{SARAN}

Bagi Pelayanan Keperawatan diharapkan menerapkan standar operasional prosedur (SOP) mobilisasi progresif dalam memberikan asuhan keperawatan pada pasien kritis untuk meminimalkan efek samping. Bagi Peneliti Selanjutnya diharapkan perlunya penelitian lebih lanjut dengan metode yang berbeda seperti mobilisasi progresif level II dan III 


\section{DAFTAR PUSTAKA}

Batticaca, FB. (2012). Asuhan Keperawatan Pada Klien Dengan Gangguan Sistem Persarafan. Jakarta : Salemba Medika

Burchell, PA. (2011). Focus on central venous pressure in acute care setting. Journal of Nursing.

Dharma, KK. (2011). Metodologi Penelitian Keperawatan: Panduan Melaksanakan Dan Menerapkan Hasil Penelitian. Jakarta : Trans Info Media

Kementerian Kesehatan Republik Indonesia. (2011). Profil Kesehatan Indonesia 2010. http://www.depkes.go.id.

Kitong, BI, dkk.(2014). Pengaruh Tindakan Penghisapan Lendir Endotrakeal Tube (Ett) Terhadap Kadar Saturasi Oksigen Pada Pasien Yang Dirawat Di Ruang Icu Rsup Prof. Dr. R. D. Kandou Manado. Jurnal keperawatan, Volume 2, No 2, 2014.

Musliha. (2010). Keperawatan Gawat Darurat. Yogyakarta : Nuha Medika

Munawaroh SW, dkk. (2012). Efektifitas Pemberian Nutrisi Enteral Metode Intermittent Feeding Dan Gravity Drip Terhadap Volume Residu Lambung Pada Pasien Kritis. Jurnal Ilmiah Kesehatan Keperawatan, Volume 8, No 3, Oktober 2012.

Pearce, EC. (2013). Buku Anatomi dan Fisiologi untuk Paramedis. Jakarta : PT Gramedia

Prayitno, H, dkk. (2015).Perbedaan Peep 5,10 Dan 15 CMH2O Terhadap Hemodinamik Pada Pasien Yang Terpasang Ventilasi Mekanik Mode Spontan Di Ruang ICU Rumah Sakit Immanuel Bandung. Immanuel Jurnal Ilmu Kesehatan Volume 9, Nomor 1, Juni 2015.

Sugiyono. (2011). Metode Penelitian Kuantitatif, Kualitatif dan R \& D. Bandung: Alfabeta.

Sunatrio. (2010). Penentuan mati pengakhiran resusitasi dan euthanasia pasif di ICU. PKGDI.Available from: http://www.freewebs.com/penentuanmati/daftarpustaka.htm Pinsky, MR. (2019). Hemodynamic Monitoring. Spinger : Switzerland 